\title{
The prevalence and risk factors associated with hypertension subtypes among ethnic Dai adults in rural China
}

\author{
Hua Zhong \\ The first affiliated hospital of Kunming Medical University \\ Yulong Dong \\ yunnan university \\ Yijin Tao \\ the first affiliated hospiatal of Kunming Medical University \\ Chen-Wei Pan \\ Medical College of Soochow University \\ Yunzhu Peng \\ the First Affiliated Hospital of Kunming Medical University \\ HongYan Cai \\ the First Affiliated Hospital of Kunming Medical University \\ Jun Li \\ The second People's Hospital of Yunnan Province \\ Yanmei Wang \\ the First Affiliated Hospital of Kunming Medical University \\ Huawei Wang \\ the First Affiliated Hospital of Kunming Medical University \\ Xun Sheng \\ Kunming Medical University \\ Feng Wang \\ Kunming Medical University \\ Lixing Chen ( $\nabla$ ydyyclx@163.com ) \\ The First Affiliated Hospital of Kunming Medical University
}

https://orcid.org/0000-0002-0746-6706

\section{Research article}

Keywords: high blood pressure (HBP), hypertension subtypes, isolated systolic hypertension (ISH), isolated diastolic hypertension (IDH), systolic-diastolic hypertension (SDH), prevalence, risk factors, awareness, treatment, control, Dai ethnic group

Posted Date: September 2nd, 2019

DOI: https://doi.org/10.21203/rs.2.13850/v1

License: (1) This work is licensed under a Creative Commons Attribution 4.0 International License. Read Full License 


\section{Abstract}

Objective Hypertension is an important risk factor for cardiovascular disease. The purpose of this survey was to determine the prevalence of hypertension subtypes and the risk factors associated with hypertension subtypes among ethnic Dai adults in rural China. Methods A population-based survey was carried out with 2150 rural inhabitants aged 50 years or older. The definition of hypertension was a systolic blood pressure (SBP) $\geq 140 \mathrm{mmHg}$ and/or a diastolic blood pressure (DBP) $\geq 90 \mathrm{mmHg}$, or a current treatment plan with an antihypertensive medication. Hypertension included the following subtypes: systolic-diastolic hypertension (SDH), isolated systolic hypertension (ISH) and isolated diastolic hypertension (IDH). All participants were interviewed, had physical examinations performed, and had blood pressure measurements taken. Multivariate logistic regression analysis was applied to analyse the risk factors for hypertension. Results The prevalence of HBP was 43.2\% (95\% Cl: 41.1-45.3). The subtype-specific prevalence of hypertension was $16.5 \%$ (95\% Cl: $14.9-18.0)$ for SDH, $24.2 \%$ (95\% Cl: $22.4-26.0)$ for ISH and $2.5 \%$ (95\% Cl: 1.9-3.2) for IDH. Among hypertensive participants, $37.9 \%$ were SDH, $56.8 \%$ were ISH and $5.8 \%$ were IDH. Older age is a risk factor for HBP and ISH. Obesity, smoking, drinking and history of hypertension are risk factors for HBP, SDH, ISH and IDH (OR>1). Of the hypertensive participants, the awareness of hypertension in our study was $25.0 \%$ for HBP, $34.7 \%$ for SDH, $20.0 \%$ for ISH and $9.3 \%$ for IDH. The rates of treatment and control were $23.8 \%$ and $6.9 \%$ for HBP, $26.8 \%$ and $7.9 \%$ for SDH, $23.1 \%$ and $6.3 \%$ for ISH and $11.1 \%$ and $5.6 \%$ for IDH, respectively. Conclusions Among Dai people in rural China, the prevalence of hypertension is high, and the awareness, treatment and control of hypertension is low. ISH is the most frequent kind of high blood pressure in rural elderly people. With the ageing population in China, ISH remains an important public health problem and a challenging issue for practising physicians in rural China. Public health strategies should regularly provide more information about hypertension to both the local physicians and the general population. To reduce cardiovascular events, a combination of drugs and lifestyle changes are strongly recommended.

\section{Background}

Hypertension is a risk factor for cardiovascular events, such as stroke, myocardial infarction, heart failure, and renal disease. The data from the China Health and Nutrition Survey (CHNS) showed that the prevalence of hypertension increased from $14.5 \%$ in 1991 to $21.4 \%$ in 2009 [1] to $25.2 \%$ in 2012 [2]. In particular, the prevalence of hypertension in rural China was $23.5 \%$, and it increased with age. The number of people with hypertension in China reached 270 million in 2012[3]. Hypertension is related to a wide phenotypic variability. Hypertension subtypes include isolated systolic hypertension (ISH), isolated diastolic hypertension (IDH) and systolicdiastolic hypertension (SDH) [4-5]. These subtypes may offer information about the predisposition of haemodynamic and/or structural abnormalities that lead to hypertension. The development of ISH is associated with increased large artery stiffness[6-7]. IDH and SDH are related to increased peripheral vascular resistance[6-7].

In China, more than half of the population resides in rural areas. Limited data are available regarding the epidemiology of hypertension subtypes among ethnic minorities in rural China. Yunnan Province is an economically developing province located in the southwestern part of China. Twenty-five ethnic groups live in Yunnan, which provides the perfect opportunity for studying ethnic disparities in various health outcomes [8]. The Dai ethnic minority is the 18th largest of 55 ethnic minority groups in China [9]. They have their own spoken language and written script [10]. Most of the Dai population live in the Xishuangbanna Autonomous Prefecture in the southern part of Yunnan Province. The prefecture is called "Aerial Garden" because of its abundant flora, fauna and tropical rain forests [11]. The Dai people are mainly involved in agriculture[11]. This study aims to determine the prevalence of hypertension subtypes and associated risk factors among the Dai ethnic people to implement early, specific, and individualized prevention strategies.

\section{Methods}

\section{Ethical considerations}

Ethical approval was granted by the Ethics Review Board of Kunming Medical University. This investigation was conducted based on the tenets of the World Medical Association's Declaration of Helsinki. All respondents signed an informed consent form before participating in the investigation.

\section{Study population and design}


In previous reports, we have described the prevalence of hypertension in adult rural Chinese populations of the Bai nationality in Dali[12] and the Yi nationality in Shilin[13]. To facilitate the comparison among different nationalities, our data collection process in the Dai ethnicity is the same as that of the Bai and Yi nationalities. The study population was composed of a random sample of Dai individuals residing in the Xishuangbanna Autonomous Prefecture. The majority of Dai nationals in China reside here, and its socioeconomic profile is representative of the Dai nationality as a whole. Information about ethnicity comes from the subjects' identity cards. The hamlet with a population of approximately 1000 served as a sample cluster. Hamlets with a population of greater than 1500 were divided and regrouped, and those with fewer than 750 were combined. Then, $10 \%$ of the total sample clusters were randomly chosen, and all Dai people over the age of 50 years in the chosen clusters were invited to participate in a physical measurement and survey questionnaire related to this study. The sample frame consisted of 111 clusters (26,328 adults over the age of 50 years), and 11 clusters (2671 adults $\geq 50$ years of age) were randomly chosen. Eventually, 2163 ethnic Dai people participated in this investigation with a response rate of $80.5 \%$.

\section{Questionnaire}

To understand the purpose of the experiment and the methods used, all researchers and staff participated in rigorous training before the epidemiological investigation. Survey data were gathered by trained research staff who were in charge of a pre-designed questionnaire. Demographic information (such as age, sex, etc.), smoking history, drinking history, hypertension history and general medical history was collected for all participants using a combined questionnaire. A face-to-face survey questionnaire included information about the diagnosis, awareness, and treatment of hypertension. The categories of smoking were modified due to a low number of participants in certain categories. Namely, "occasional smoking" was classified as non-smoking and "quitting smoking" was classified as smoking. Alcohol consumption $\geq 8 \mathrm{~g} /$ week was defined as drinking [14]. One parent having hypertension was defined as a family history of hypertension.

\section{Blood pressure and hypertension subtype measurement}

Based on a standardized process, a trained researcher measured the resting blood pressure of all participants. Cuff sizes were chosen according to the subjects' arm circumference. Subjects were sitting for at least 15 minutes to rest before the measurements were taken. At the same time, 30 minutes before their blood pressure was measured, subjects were asked to avoid smoking, drinking, caffeinated beverages, and exercise. Measurements were repeated at a time interval of every three minutes. Hypertension was defined as a SBP greater than or equal to $140 \mathrm{mmHg}$, and/or a DBP greater than or equal to $90 \mathrm{mmHg}$, or a current treatment with an antihypertensive medication[15]. Hypertension subtypes were included in the following categories: (1) isolated systolic hypertension (ISH) was defined as a SBP greater than or equal to $140 \mathrm{mmHg}$ and a DBP less than $90 \mathrm{mmHg}$; (2) isolated diastolic hypertension (IDH) was defined as a SBP less than $140 \mathrm{mmHg}$ and a DBP greater than or equal to $90 \mathrm{mmHg}$; (3) systolic-diastolic hypertension (SDH) was defined as a SBP greater than or equal to $140 \mathrm{mmHg}$ and a DBP greater than or equal to $90 \mathrm{mmHg}[4-5]$. Hypertension awareness was defined as the subject's self-report of any previous diagnosis of hypertension by a medical professional. Hypertension treatment was defined as the subject's self-report of taking hypertensive drugs. Hypertensive participants who were under treatment and had a blood pressure less than 140/90 mmHg were defined as hypertension control subjects.

\section{Measurement of body size}

Wearing no shoes and light clothing, the height and weight of participants were measured. Body mass index (BMI) was equal to weight in kilograms divided by height in square metres. $\mathrm{BMI}<18.50,18.5-24.99$ and $\geq 25.00 \mathrm{~kg} / \mathrm{m}^{2}$ represent the categories of a leanness, normal weight, and obesity, respectively[16].

\section{Statistical analysis}

In each subgroup, continuous variables were expressed as the mean \pm SD and categorical variables were expressed as the rate or percentage. Continuous variables between two groups were analysed by applying the t-test, while those among three groups or 
more were analysed by applying one-way ANOVA. Associations between categorical variables were analysed using Chi-square tests. Applying multivariate logistic regression models, we calculated the adjusted odds ratios (OR) with $95 \%$ confidence intervals $(95 \% \mathrm{Cl})$ for high blood pressure status. All data were calculated by applying SAS software (Version 9.1; SAS Institute Inc., Cary, NC, USA). All statistical data were two-tailed, and a p-value less than 0.05 was regarded as being statistically significant.

\section{Results}

\section{Basic characteristics of the sample population.}

In total, 2688 Dai people aged $\geq 50$ years were counted, and 2163 (80.5\%) subjects were successfully examined. The majority of respondents were female (female vs. male: $96.7 \%$ vs. $62.5 \%$ ) and tended to be older. The main reasons for fewer male participants and fewer younger subjects were a lack of interest in the project or being too busy to participate (Table 1). The average age of both sexes was $63.6 \pm 10.0$ years. The average age between males and females (63.5 \pm 9.4 vs $63.6 \pm 10.4$ years) was not significantly different ( $p>0.05$ ). Compared to females, the males demonstrated higher mean values of DBP, height, weight and proportions of obesity, smoking, drinking, and family history of hypertension $(p<0.05)$ (Table 2).

\section{Hypertension subtype prevalence}

The prevalence of HBP was 43.2\% (928/2150; 95\% Cl: 41.1-45.3). The subtype-specific prevalence of hypertension was $16.5 \%$ (354/2150; 95\% Cl: 14.9-18.0) for SDH, 24.2\% (520/2150; 95\% Cl: 22.4-26.0) for ISH and 2.5\% (54/2150; 95\% Cl: 1.9-3.2) for IDH. Among hypertensive participants, 37.9\% (354/928) were SDH, 56.8\% (520/928) were ISH and 5.8\% (54/928) were IDH (Table 2).

The prevalence of HBP in the different age groups (50-59 years, $60-69$ years and 70 years or older) was $34.4 \%, 45.5 \%$ and $52.5 \%$ for HBP; $17.0 \%, 18.0 \%$ and $14.0 \%$ for SDH; $14.5 \%, 25.2 \%$ and $36.3 \%$ for ISH; and $2.9 \%, 2.3 \%$ and $2.3 \%$ for IDH, respectively. The prevalence of HBP in the different sex (male and female) groups was $45.9 \%$ and $41.6 \%$ for HBP; $22.2 \%$ and $13.2 \%$ for SDH; $20.0 \%$ and $26.6 \%$ for ISH; and $3.7 \%$ and $1.8 \%$ for IDH, respectively. The prevalence of HBP in the different body weight groups (lean, normal weight, obese) was $37.7 \%, 44.4 \%$ and $52.8 \%$ for HBP; $10 \%, 18.3 \%$ and $25.5 \%$ for SDH; $12.5 \%, 17.3 \%$ and $22.2 \%$ for ISH; and $1.2 \%, 2.7 \%$ and $5.2 \%$ for IDH, respectively. The prevalence of subjects with a family history of hypertension or those with drinking habits or smoking habits was $72.0 \%, 55.1 \%$ and $61.9 \%$ for HBP; $38.2 \%, 23.9 \%$ and $27.2 \%$ for $\mathrm{SDH} ; 32.3 \%, 26.0 \%$ and $31.4 \%$ for ISH; and $2.7 \%, 5.2 \%$ and 3.35 for IDH, respectively. However, the prevalence of those without a family history of hypertension or those without drinking habits or smoking habits was $38.1 \%, 40.1 \%$ and $36.3 \%$ for $\mathrm{HBP} ; 12.6 \%, 14.5 \%$ and $12.5 \%$ for SDH; $22.8 \%, 23.7 \%$ and $21.6 \%$ for ISH; and $1.6 \%, 1.8 \%$ and $2.2 \%$ for IDH (Table 4 ).

\section{SBP, DBP and pulse pressure among different groups}

The SBP value in the age group 50-59 years $(140.2 \pm 24.8 \mathrm{mmHg})$ was lower than those of the other two groups (age group 60-69 years: $147.0 \pm 26.9 \mathrm{mmHg}$, age group 70 years or older: $150.6 \pm 24.7 \mathrm{mmHg})(p<0.05)$. The values of DBP among different ages were not significantly different $(p>0.05)$. The values of SBP $(142.3 \pm 25.4 \mathrm{mmHg})$ and DBP $(78.8 \pm 13.4 \mathrm{mmHg})$ in the lean group were lower than those of the other two groups (normal group: $146.2 \pm 26.1 \mathrm{mmHg}$ for SBP, $83.3 \pm 13.9 \mathrm{mmHg}$ for DBP; obese group: $150.3 \pm 25.4 \mathrm{mmHg}$ for SBP, $87.9 \pm 15.8 \mathrm{mmHg}$ for DBP) ( $p<0.05)$. The DBP readings of males $(85.1 \pm 15.3 \mathrm{mmHg})$ were higher than those of females $(80.9 \pm 13.4 \mathrm{mmHg})(p<0.05)$. Subjects with a family history of hypertension or those with a habit of smoking or drinking had higher SBP and DBP readingscompared with those without a family history of hypertension or with no habit of smoking or drinking $(p=0.000)$. Pulse pressure readings increased with age $(p=0.000)$. Pulse pressure readings among subjects with a family history of hypertension or a habit of smoking were higher than those without a family history or smoking habit $(p=$ 0.000)(Table 3).

\section{Risk factors of hypertension subtypes}

To further investigate the risk factors of various hypertension subtypes, HBP, SDH, ISH and IDH were applied as the dependent variable, while sex, age, BMI, smoking habit, drinking habit, and family history of HBP were used as the independent variables. The 
data were analysed by using multivariate logistic regression models (Table 4), with adjustments for all of the variables. Subjects in the age groups of 60-69 years and 70 years or older $(60-69,70+)$ tended to have a higher risk of HBP and ISH $(0 R>1.0)$ compared with the age group of 50-59 years. People with obesity were prone to a higher risk of developing HBP, SDH, ISH, and IDH $(\mathrm{OR}>1.0)$ than participants with a normal weight. Participants with a family history of hypertension or those who drank or smoked had a much greater chance of developing HBP, SDH and ISH $(O R>1.0)$ compared to those without a family history of hypertension or who did not drink or smoke. Females tended to have a higher risk of HBP and ISH (OR > 1.0) compared to males. Drinking is a risk factor for IDH (OR > 1.0) (Table 4).

\section{Hypertension awareness, treatment, and control}

The prevalence of awareness among subjects with hypertension was 25.0\% (232/928) for HBP, 34.7\% (123/354) for SDH, 20.0\% $(104 / 520)$ for ISH and 9.3\% (5/54) for IDH. Of the participants with hypertension, 23.8\% (221/928) took antihypertensive medications, and $6.9 \%(64 / 928)$ of them reached a normal blood pressure with the use of medications. Of the participants with $\mathrm{SDH}, 26.8 \%$ (95/354) took antihypertensive drugs, and 7.9\% (28/354) of them had normal blood pressure. Among the participants with ISH, the rates of treatment and control were $23.1 \%(120 / 520)$ and $6.3 \%(33 / 520)$, respectively. Among the IDH participants, the rates of treatment and control were $11.1 \%(6 / 54)$ and $5.6 \%(3 / 54)$, respectively (Table 5$)$

\section{Discussion}

This investigation offers population-based data on the epidemiology of hypertension in older Dai adults in rural China. The rate of HBP among the Dai people aged 50 years or older was $43.2 \%$. The subtype-specific prevalence of hypertension was $16.5 \%$ for SDH, $24.2 \%$ for ISH and $2.5 \%$ for IDH. Among all the hypertension patients, $37.9 \%$ were SDH, 56.8\% were ISH and 5.8\% were IDH. ISH was the most common kind of high blood pressure in rural elderly people, followed by SDH. In comparison with the age group of 50-59 years, Dai people in the age groups of 60-69 years and 70+ years were prone to a higher risk of ISH (OR > 1.0). However, along with the increase in age, SDH and IDH prevalence did not indicate an increasing trend $(P>0.05)$. Among Dai people aged over 50 years, the SBP value tended to increase, and the DBP value tended to decrease, which led to a widening of the pulse pressure. The rigidity of large arteries (including the aorta) appeared to increase with age. The SBP value appeared to increase with age, which caused an increased incidence of ISH in elderly people[7]. SBP is one of the most important cardiovascular risks and reflects diffuse atherosclerotic processes[6]. If SBP declines by $10 \mathrm{mmHg}$, major cardiovascular disease events will decline by $20 \%$, heart failure will decline by $18 \%$, coronary heart disease will decline by $17 \%$, stroke will decline by $17 \%$ and all-cause mortality will decline by $13 \%$ [17]. From 1979 to 2015 , the Chinese government had carried out a one-child policy to curb China's population growth, which has led to changes in the demographic structure and ageing population in China. In accordance with the United Nations, an ageing society is one in which more than $7 \%$ of the total population is over 65 years old. According to the 2010 census of the Chinese population, $13.31 \%$ of the total population is aged 60 years, and $14.98 \%$ of the rural population is aged over 60 years[18]. It is estimated that a quarter of the population will be 60 years or older by 2030 in China. Because of the increasing ageing population in China, the prevalence of hypertension, particularly ISH, is anticipated to increase significantly, which means that the ISH burden is rapidly rising. Therefore, ISH remains an important public health concern in China.

Compared to people with a normal weight, the prevalence of HBP, SDH, ISH and IDH among Dai people with obesity showed increasing trends $(p<0.05)$. The prevalence of HBP, SDH, ISH and IDH among Dai people with obesity was $52.8 \%, 25.5 \%, 22.2 \%$ and $5.2 \%$, respectively. Both SBP and DBP values increase with increasing BMI. The Dai people are mainly involved with agriculture. During busy seasons, their diet usually consists of a large amount of meat, which is high in saturated fat and cholesterol. The farmers think that high-fat dairy foods give them strength. Most Dai people do not have the awareness of the benefits of regular exercise. Most of them remain sedentary in their leisure time. Therefore, the guidance of maintaining a healthy diet and regular exercise is important in helping Dai people control their weight and prevent hypertension. Dai people should take part in accumulated moderate-intensity aerobic physical exercise $\geq 150$ minutes /week [19]. At the same time, they should keep healthy diets abundant in dark green vegetables, fresh fruits, whole grains (instead of refined grains), and low-fat and low-sodium dairy options [19].

Dai people who drank or smoked had a higher prevalence of HBP, SDH, ISH and IDH $(P=0.000)$ compared with those who did not drink or smoke. Wine culture is an important part of the national etiquette. Dai people are particularly good at brewing liquor. Dai

Page 5/11 
people like to drink in large bowls in their daily life, during festivals, and for social reasons or entertainment. The drinking rate for Dai males over 50 years old is $45.6 \%$. Through health education, it is best to reduce the frequency and amount of each drink as well as to abstain from alcohol altogether. In addition, the smoking rate among Dai people over 50 years old is $26.3 \%$ ( $50.1 \%$ for males and $13.4 \%$ for females). According to the Chinese Adult Tobacco Survey in 2015, the smoking rate of people over 15 years old was $27.7 \%$ (52.1\% for males and $2.7 \%$ for females)[3]. The smoking rate of elderly Dai women is obviously higher than that of the whole country. Dai people think that it is normal for women to smoke, and some women have the habit of chewing tobacco as well. The high smoking rate is related to Dai people's cultural customs and insufficient awareness of the hazards of smoking. Smoking is an important independent risk factor for hypertension and premature death [19]. Tobacco dependence is a chronic disease. Healthcare professionals should provide some ways (including behavioural interventions and medicine) to help people quit smoking [19]. In addition, it is important to reduce second-hand smoke exposure of non-smokers through health campaigns.

Of hypertensive participants, the awareness in our study was 25.0\% (232/928) for HBP, 34.7\% (123/354) for SDH, 20.0\% (104/520) for ISH and 9.3\% (5/54) for IDH, which was much lower than that reported in urban northwest China (42.9\%) [20], Thailand (43.9\%) [21], the USA (69\%)[22], London (44\%)[23] and South Korea (60.1\%)[24]. Perhaps the reasons were as follows. The Dai ethnic population in our study resided in rural southwest China. They often had a lower level of education and a lack of basic health knowledge. Few of them realized that they have hypertension because of no symptoms. Therefore, undiscovered hypertensive patients accounted for a significant proportion. Due to their lower income, many people were not willing to go to the hospital, which indicates that in the early phase, a large number of hypertensive patients were not found.

Of the participants with hypertension, 23.8\% (221/928) had HBP, 26.8\% (95/354) had SDH, 23.1\% (120/520) had ISH and 11.1\% (6/54) took antihypertensive medications. The rates of control were $6.9 \%$ for HBP, $7.9 \%$ for SDH, $6.3 \%$ for ISH and $5.6 \%$ for IDH. The rates of treatment and control of hypertension in the population aged over 18 years in 2012 in China were $41.1 \%$ and 13.8\%, respectively[2]. Dai people have lower rates of treatment and control. There are some reasons for this phenomenon. First, the hypertension awareness of those participants who were diagnosed with hypertension was very low. The examination of blood pressure is not still fully covered by current health insurance companies. Second, classic antihypertensive drugs are involved in calcium channel blockers, angiotensin-converting enzyme inhibitors, angiotensin receptor blockers, $\beta$-blockers and thiazide diuretics. Long-term antihypertensive drugs are better than short-term drugs. For economic reasons, Dai people prefer to choose short-term antihypertensive medicines, such as hydrochlorothiazide, captopril and captopril. When attempting to control SBP with antihypertensive medicine in older people with high blood pressure, physicians may worry about the underlying negative effects of exceeding a decline in DBP. Some doctors lack a comprehensive understanding of the significance of SBP control, which may decrease the effectiveness of hypertension treatment. Third, Xishuangbanna is a tropical rainforest climate with abundant animal and plant resources. Some Dai people prefer Chinese herbal medicine to treat hypertension. In addition, most of them do not have knowledge about keeping their blood pressures normal. When their blood pressure was found to be "normal", they would stop antihypertensive therapy. Thus, the frequency and number of patient follow-ups decreased. Most patients did not make sufficient lifestyle changes.

Some limitations of this study need to be acknowledged. First, because we only visited the subject once, white-coat hypertension (when a patient sees a doctor, his/her blood pressure will elevate) and secondary hypertension were not eliminated from the hypertensive group. Second, our study conducted a population-based survey based on randomly selected samples. We could not determine whether there was a nonresponse selection bias. Data on smoking habits, alcohol drinking habits, salt intake and exercise routines were in accordance with self-report, and biological measurements or specific tests were not performed, which could lead to misclassification due to recall bias. Furthermore, due to the cross-sectional design of this study, we did not infer cause and effect.

In conclusion, hypertension prevalence is high among Dai people in rural China. Most of the hypertensive Dai people didn't realize that they had hypertension. The prevalence of treatment and control was low. ISH was the most common kind of hypertension in the rural elderly population. Coupled with China's ageing population, ISH remains to be a primary public health problem and a challenging issue for practising physicians in rural China. Older age, obesity, smoking, drinking and a history of hypertension are all risk factors for ISH. Public health strategies should regularly provide more information to both local physicians and the general population on how to prevent hypertension and encourage people to monitor and track their blood pressure and to follow the 
advice of medical experts. A combination of drugs and lifestyle modifications should be strongly recommended to reduce cardiovascular events.

\section{Abbreviations}

BMI, Body mass index; HBP, High blood pressure; ORs, Odds ratios

\section{Declarations}

\section{Competing interests}

The authors claim that they have no competing interests.

\section{Authors' contributions}

Hua Zhong and Lixing Chen conceptualized and designed the survey, conducted the statistical analyses, drafted the first manuscript and approved the final manuscript as submitted. Yulong Dong conducted the statistical analyses, was conducive to explaining the data analysis and drafted the first manuscript. Yijin Tao and Chen-Wei Pan have been involved in drafting the manuscript. Yunzhu Peng, HongYan Cai and Jun Li conducted the statistical analyses. Yanmei Wang, Huawei Wang, Xun Sheng and Feng Wang conducted the data collection. All authors agreed to the submission of the final manuscript.

\section{Acknowledgements}

The investigation was subsidized by the Natural Science Foundation of Yunnan Province under grant No. 2017FE467(-027), and the Science Foundation of National Health and Family Planning Commission of Yunnan Province under grant No. 2016NS016. This investigation was also subsidized by the National Natural Science Foundation of China under grant No. 81773449 and No. 81560169.

\section{References}

1. Xi B, Liang Y, Reilly KH, et al. Trends in prevalence, awareness, treatment, and control of hypertension among Chinese adults 1991-2009. Int J Cardiol. 2012; 158:326-329.

2. Disease Prevention and Control Bureau of the State Health and Family Planning Commission. Report on Nutrition and Chronic Diseases of Chinese Residents (2015). People's Health Publishing House,2015.

3. China Cardiovascular Disease Report Writing Group. Summary of China Cardiovascular Disease Report (2017). Chinese Circulation Journal (Chinese). 2018.33: 1-8

4. Franklin SS, Pio JR, Wong ND, et al. Predictors of new-onset diastolic and systolic hypertension: the Framingham Heart Study. Circulation 2005; 111: 1121-1127.

5. Franklin SS, Jacobs MJ, Wong ND, et al. Predominance of isolated systolichypertension among middle-aged and elderly US hypertensives: analysis based on National Health and Nutrition Examination Survey (NHANES) III. Hypertension.2001;37:869874.

6. Verdecchia P, Angeli F.Natural history of hypertension subtypes.Circulation. 2005; 111:1094-6.

7. Saladini F, Dorigatti F, Santonastaso M, et al. Natural history of hypertension subtypes in young and middle-age adults. Am J Hypertens 2009;22:531-7.

8. China Today. Yunnan Province. Available: http://www.chinatoday.com/city/ yunnan.htm.Accessed 2016 Oct 30.

9. National Bureau Statistics of the People's Republic of China. Available: http://www.stats.gov.cn/tjsj/pcsj/rkpc/5rp/index.htm. Accessed:2000 Jan1

10. China Ethnicity Net. The Dai Nationality. Available:http://www.minzu56.net/dzu/. Accessed: 2014 Dec 2

Page $7 / 11$ 
11. China highlights. Xishuangbanna Travel Guide. http://www.chinahighlights.com/ xishuangbanna/.Accessed:2015 Oct 16.

12. Zhang J, Huang Q, Yu M, Cha X, Zhong H, et al. Prevalence, awareness, medication, control, and risk factors associated with hypertension in Bai ethnic group in rural China: the Yunnan minority eye study. PLoS One. 2013;8(8):1-9.

13. Chen L, Zong Y, Wei T, Sheng $X$, Zhong H, et al. Prevalence, awareness, medication, control, and risk factors associated with hypertension in Yi ethnic group in rural China: the Yunnan minority eye study.BMC Public Health. 2015, 15(1):1-9

14. National institute on Alcohol Abuse and Alcoholism. Health risks and benefits of alcohol consumption. Alcohol Res Health. 2000;24(1):5-11.

15. Chobanian AV, Bakris GL, Black HR, Cushman WC, Green LA, et al. The seventh report of the joint National Committee on Prevention, Detection, Evaluation, and Treatment of High Blood Pressure: the JNC 7 report. JAMA. 2003;289:2560-2572.

16. WHO. BMI classification.http://apps.who.int/bmi/index.jsp?introPage = intro_3. Html. Accessed 2013Jan 21

17. Kengne AP, Patel A, Barzi F, Jamrozik K, Lam TH, Ueshima H, Gu DF, Suh I, Woodward M. Systolic blood pressure, diabetes and the risk of cardiovascular diseases in the Asia-Pacific region. J Hypertens 2007; 25: 1205-1213.

18. National Bureau Statistics of the People's Republic of China. Available: http://www.stats.gov.cn/tjsj/pcsj/rkpc/6rp/indexch.htm. Accessed:2019 Feb1.

19. Albert MA, Buroker AB, Goldberger ZD, et al.2019 ACC/AHA Guideline on the Primary Prevention of Cardiovascular Disease.Circulation.2019.1-98.

20. Meng XJ, Dong GH, Wang D, Liu MM, Lin Q, et al. Prevalence, awareness, treatment, control, and risk factors associated with hypertension in urban adults from 33 communities of China: the CHPSNE study. J Hypertens. 2011;29:1303-10.

21. Porapakkham Y, Pattaraarchachai J, Aekplakorn W. Prevalence, awareness, treatment and control of hypertension and diabetes mellitus among the elderly: the 2004 National Health Examination Survey III, Thailand. Singapore Med J. 2008;49:868-73.

22. Burt VL, Whelton P, Roccella EJ, Brown C, Cutler JA, et al. Prevalence of hypertension in the US adult population. Results from the third National Health and Nutrition Examination Survey, 1988-1991.Hypertension. 1995;25:305-13.

23. Costanzo S, Di Castelnuovo A, Zito F, Krogh V, Siani A, et al. Prevalence, awareness, treatment and control of hypertension in healthy unrelated male-female pairs of European regions: the dietary habit profile in European communities with different risk of myocardial infarction-the impact of migration as a model of gene-environment interaction project. J Hypertens. 2008;26:2303-11

24. Lee HS, Park YM, Kwon HS, Lee JH, Park YJ, et al. (2010) Prevalence, awareness, treatment, and control of hypertension among people over 40 yearsold in a rural area of South Korea: The Chungju Metabolic Disease Cohort (CMC) Study. ClinExpHypertens 32: 166-178

25. Health Network. http://m.39.net/disease/a_7168817.html.Accessed:2019 Jun 5.

\section{Tables}

Table 1. Basic characteristics of the sample population

\begin{tabular}{|l|l|l|l|l|}
\hline & Male $(\mathrm{n}=789)$ & Female $(\mathrm{n}=1360)$ & Total $(\mathrm{n}=2150)$ & $\mathrm{p}$ \\
\hline Age $($ years $)$ & $63.5 \pm 9.4$ & $63.6 \pm 10.4$ & $63.6 \pm 10.0$ & 0.644 \\
\hline Height(cm) & $163.4 \pm 8.1$ & $154.2 \pm 14.5$ & $157.6 \pm 13.3$ & 0.000 \\
\hline Weight(kg) & $56.0 \pm 11.2$ & $48.3 \pm 9.9$ & $51.1 \pm 21.5$ & 0.000 \\
\hline SBP(mmHg) & $146.8 \pm 21.2$ & $144.6 \pm 25.8$ & $145.4 \pm 25.9$ & 0.062 \\
\hline DBP(mmHg) & $85.1 \pm 15.3$ & $80.9 \pm 13.4$ & $82.4 \pm 14.2$ & 0.000 \\
\hline Pulse pressure $(\mathrm{mmHg})$ & $61.6 \pm 19.9$ & $63.8 \pm 20.2$ & $63.0 \pm 20.1$ & 0.015 \\
\hline BMI $(\mathrm{kg} / \mathrm{m} 2)$ & $21.4 \pm 13.5$ & $20.6 \pm 7.8$ & $20.9 \pm 10.3$ & 0.070 \\
\hline BMI $\geq 25(\mathrm{n}, \%)$ & $96(12.2)$ & $116(8.5)$ & $212(9.9 \%)$ & 0.002 \\
\hline Cigarette smoking & $395(50.1)$ & $182(13.4)$ & $577(26.8)$ & 0.000 \\
\hline Alcohol consumption & $360(45.6)$ & $83(6.1)$ & $443(20.6)$ & 0.000 \\
\hline Family history of HBP & $146(18.5)$ & $176(12.9)$ & $322 \square 15 \% \square$ & 0.000 \\
\hline
\end{tabular}

Note: data presented as the mean \pm SD or \%.

$\mathrm{P}$ values for comparisons between males and females, performed using a Chi-square test 
Table 2. Study population by age, sex and prevalence of hypertension subtypes

\begin{tabular}{|c|c|c|c|c|c|c|c|c|c|c|c|}
\hline & \multirow{2}{*}{$\begin{array}{l}\text { Enumerated } \\
\text { No. (\%) }\end{array}$} & \multirow{2}{*}{$\begin{array}{l}\text { Examined } \\
\text { No. (\%) }\end{array}$} & \multirow{2}{*}{$\begin{array}{l}\text { \%Examination } \\
\text { Response } \\
\text { Rate }\end{array}$} & \multicolumn{2}{|c|}{$\mathrm{HBP}$} & \multicolumn{2}{|c|}{$\mathrm{SDH}$} & \multicolumn{2}{|l|}{ ISH } & \multicolumn{2}{|c|}{ IDH } \\
\hline & & & & $\begin{array}{l}\text { Prevalence } \\
\text { of No. (\%) }\end{array}$ & $\begin{array}{l}(95 \% \\
\mathrm{CI})\end{array}$ & $\begin{array}{l}\text { Prevalence } \\
\text { of No. (\%) }\end{array}$ & $\begin{array}{l}(95 \% \\
\mathrm{CI})\end{array}$ & $\begin{array}{l}\text { Prevalence } \\
\text { of No. (\%) }\end{array}$ & $\begin{array}{l}(95 \% \\
\mathrm{CI})\end{array}$ & $\begin{array}{l}\text { Prevalence } \\
\text { of No. (\%) }\end{array}$ & $\begin{array}{l}(95 \% \\
\text { CI) }\end{array}$ \\
\hline \multicolumn{12}{|l|}{ Sex } \\
\hline Male & $1276(47.5)$ & 797(36.8) & 62.5 & $362(45.9)$ & $\begin{array}{l}42.4- \\
49.4\end{array}$ & $175(22.2)$ & $\begin{array}{l}19.3- \\
25.1\end{array}$ & 158(20.0) & $\begin{array}{l}17.2- \\
22.8\end{array}$ & $29(3.7)$ & $\begin{array}{l}2.4- \\
5.0\end{array}$ \\
\hline Female & $1412(52.5)$ & $1366(63.2)$ & 96.7 & $566(41.6)$ & $\begin{array}{l}39.0- \\
44.2 \\
\end{array}$ & 179(13.2) & $\begin{array}{l}11.4- \\
15.0\end{array}$ & $362(26.6)$ & $\begin{array}{l}24.3- \\
29.0\end{array}$ & $25(1.8)$ & $\begin{array}{l}1.1- \\
2.6\end{array}$ \\
\hline Total & $2688(100.0)$ & $2163(100.0)$ & 80.5 & $928(43.2)$ & $\begin{array}{l}41.1- \\
45.3 \\
\end{array}$ & $354(16.5)$ & $\begin{array}{l}14.9- \\
18.0 \\
\end{array}$ & $520(24.2)$ & $\begin{array}{l}22.4- \\
26.0 \\
\end{array}$ & $54(2.5)$ & $\begin{array}{l}1.9- \\
3.2 \\
\end{array}$ \\
\hline \multicolumn{12}{|c|}{ Age (years) } \\
\hline $50-59$ & $1167(43.4)$ & $840(38.8)$ & 72.0 & $289(34.4)$ & $\begin{array}{l}31.2- \\
37.6 \\
\end{array}$ & $143(17.0)$ & $\begin{array}{l}14.5- \\
19.6\end{array}$ & 122(14.5) & $\begin{array}{l}12.1- \\
16.9\end{array}$ & $24(2.9)$ & $\begin{array}{l}1.7- \\
4.0\end{array}$ \\
\hline $60-69$ & $810(30.1)$ & 695(32.1) & 85.8 & $316(45.5)$ & $\begin{array}{l}41.8- \\
49.2 \\
\end{array}$ & $125(18.0)$ & $\begin{array}{l}15.1- \\
20.9 \\
\end{array}$ & $175(25.2)$ & $\begin{array}{l}22.0- \\
28.5 \\
\end{array}$ & $16(2.3)$ & $\begin{array}{l}1.1- \\
3.4 \\
\end{array}$ \\
\hline $70+$ & $711(26.5)$ & $628(29.1)$ & 86.5 & $323(52.5)$ & $\begin{array}{l}48.5- \\
56.5\end{array}$ & $86(14.0)$ & $\begin{array}{l}11.2- \\
16.7\end{array}$ & $223(36.3)$ & $\begin{array}{l}32.5- \\
40.1\end{array}$ & $14(2.3)$ & $\begin{array}{l}1.1- \\
3.5\end{array}$ \\
\hline Total & $2688(100.0)$ & $2163(100.0)$ & 80.5 & $928(43.2)$ & $\begin{array}{l}41.1- \\
45.2 \\
\end{array}$ & $354(16.5)$ & $\begin{array}{l}14.0- \\
18.0 \\
\end{array}$ & $520(24.2)$ & $\begin{array}{l}22.4- \\
26.0 \\
\end{array}$ & $54(2.5)$ & $\begin{array}{l}1.9- \\
3.2 \\
\end{array}$ \\
\hline
\end{tabular}

Note: HBP, high blood pressure; ISH, isolated systolic hypertension; IDH, isolated diastolic hypertension; SDH, systolic-diastolic hypertension

Table 3. Comparisons of the values of SBP, DBP and pulse pressure for different groups

\begin{tabular}{|c|c|c|c|c|c|c|c|c|c|c|}
\hline & $\mathrm{n}$ & $\mathrm{SBP}(\mathrm{mmHg})$ & $\mathrm{T}$ & $\mathrm{P}$ & $\mathrm{DBP}(\mathrm{mmHg})$ & $\mathrm{T}$ & $\mathrm{P}$ & pulse pressure (mmHg) & $\mathrm{T}$ & $\mathrm{P}$ \\
\hline \multicolumn{11}{|c|}{$\begin{array}{lll} & 1 \\
\end{array}$} \\
\hline Male & 787 & $146.8 \pm 26.2$ & 1.866 & 0.062 & $85.1 \pm 15.3$ & 6.665 & $0.000 \mathrm{a}$ & $61.6 \pm 19.9$ & -2.446 & $0.015 a$ \\
\hline Female & 1360 & $144.6 \pm 25.8$ & & & $80.9 \pm 13.4$ & & & $63.8 \pm 20.2$ & & \\
\hline \multicolumn{11}{|c|}{ Age (years) } \\
\hline $50-59$ & 840 & $140.2 \pm 24.8$ & $5.151 \mathrm{a}$ & $0.000 \mathrm{a}$ & $83.0 \pm 14.0$ & $0.114 \mathrm{a}$ & $0.910 \mathrm{a}$ & $57.2 \pm 17.6$ & $-6.881 \mathrm{a}$ & $0.000 \mathrm{a}$ \\
\hline $60-69$ & 692 & $147.0 \pm 26.9$ & $-2.626 \mathrm{~b}$ & $0.022 \mathrm{~b}$ & $83.0 \pm 14.87$ & $2.592 \mathrm{~b}$ & $0.059 \mathrm{~b}$ & $63.9 \pm 20.6$ & $-5.317 b$ & $0.000 \mathrm{~b}$ \\
\hline $70+$ & 451 & $150.6 \pm 24.7$ & $-8.010 \mathrm{C}$ & $0.000 \mathrm{c}$ & $81.32 \pm 13.6$ & $2.908 \mathrm{c}$ & $0.033 \mathrm{c}$ & $69.9 \pm 20.4$ & $-12.733 \mathrm{c}$ & $0.000 \mathrm{C}$ \\
\hline \multicolumn{11}{|c|}{ Body weight } \\
\hline Normal & 1283 & $146.2 \pm 26.1$ & $3.153 \mathrm{a}$ & $0.002 \mathrm{a}$ & $83.3 \pm 13.9$ & $6.912 \mathrm{a}$ & $0.000 \mathrm{a}$ & $62.8 \pm 20.1$ & $-0.772 \mathrm{a}$ & $0.440 \mathrm{a}$ \\
\hline Lean & 652 & $142.3 \pm 25.4$ & $-3.952 \mathrm{~b}$ & $0.000 \mathrm{~b}$ & $78.8 \pm 13.4$ & $-8.252 \mathrm{~b}$ & $0.000 \mathrm{~b}$ & $63.5 \pm 20.7$ & $0.761 \mathrm{~b}$ & $0.447 \mathrm{~b}$ \\
\hline Obese & 212 & $150.3 \pm 25.4$ & $-2.090 \mathrm{c}$ & $0.000 \mathrm{c}$ & $87.9 \pm 15.8$ & $-4.366 \mathrm{c}$ & $0.037 \mathrm{C}$ & $62.3 \pm 18.7$ & $0.314 \mathrm{c}$ & $0.754 \mathrm{c}$ \\
\hline \multicolumn{11}{|c|}{ Cigarette smoking } \\
\hline No & 1572 & $142.5 \pm 25.3$ & -8.778 & 0.000 & $80.8 \pm 13.7$ & -8.823 & 0.000 & $61.7 \pm 19.7$ & -4.786 & 0.000 \\
\hline Yes & 575 & $153.4 \pm 26.0$ & & & $86.8 \pm 14.8$ & & & $66.4 \pm 20.9$ & & \\
\hline \multicolumn{11}{|c|}{ Alcohol consumption } \\
\hline No & 443 & $144.3 \pm 26.1$ & -3.891 & 0.000 & $81.3 \pm 14.0$ & -7.019 & 0.000 & $62.9 \pm 20.2$ & -0.157 & 0.875 \\
\hline Yes & 1704 & $149.7 \pm 24.7$ & & & $86.6 \pm 14.3$ & & & $63.1 \pm 19.8$ & & \\
\hline \multicolumn{11}{|c|}{ Family history of HBP } \\
\hline No & 320 & $142.2 \pm 24.5$ & -14.3 & 0.000 & $80.9 \pm 13.4$ & -12.3 & 0.000 & $61.4 \pm 19.5$ & -9.030 & 0.000 \\
\hline Yes & 1827 & $163.7 \pm 26.5$ & & & $91.2 \pm 15.7$ & & & $72.1 \pm 21.1$ & & \\
\hline
\end{tabular}

Note: a. P for Age 50-59 vs 60-69, or for Normal vs Lean, b. P for age 60-69 vs 70+, or for Lean vs Obese, c. P for Age 50-59 vs $70+$, or for Normal vs Obese

Table 4. Percentage (\%) of hypertension subtypes by socio-demographics and risk factors 


\begin{tabular}{|c|c|c|c|c|c|c|c|c|}
\hline & $\begin{array}{l}\text { Prevalence of HBP } n \\
(\%)\end{array}$ & $\mathrm{p}$ & $\begin{array}{l}\text { Prevalence of SDH n } \\
\text { (\%) }\end{array}$ & $\mathrm{p}$ & $\begin{array}{l}\text { Prevalence of ISH } \\
n(\%)\end{array}$ & $\mathrm{p}$ & $\begin{array}{l}\text { Prevalence of IDH } \\
\text { n(\%) }\end{array}$ & $\mathrm{p}$ \\
\hline \multicolumn{9}{|l|}{ Sex } \\
\hline Male(reference) & $362(45.9)$ & 0.03 & $175(22.2)$ & 0.000 & $158(20.0)$ & 0.000 & $29(3.7)$ & 0.007 \\
\hline Female & $566(41.6)$ & & $179(13.2)$ & & $362(26.6)$ & & $25(1.8)$ & \\
\hline \multicolumn{9}{|c|}{ Age groups (years) } \\
\hline $\begin{array}{l}50-59 \\
\text { (reference) }\end{array}$ & $289(34.4)$ & 0.000 & $143(17.0)$ & 0.126 & 122(14.5) & 0.000 & $24(2.9)$ & 0.716 \\
\hline $60-69$ & $316(45.5)$ & & $125(18.0)$ & & $175(25.2)$ & & $16(2.3)$ & \\
\hline $70+$ & $323(52.5))$ & & $86(14.0)$ & & $223(36.3)$ & & $14(2.3)$ & \\
\hline \multicolumn{9}{|l|}{ Body weight } \\
\hline $\begin{array}{l}\text { Normal } \\
\text { (reference) }\end{array}$ & $570(44.4)$ & 0.000 & $235(18.3)$ & 0.000 & $300(17.3)$ & 0.002 & $35(2.7)$ & 0.004 \\
\hline Lean & $246(37.7)$ & & $65(10.0)$ & & $173(12.5)$ & & $8(1.2)$ & \\
\hline Obese & $112(52.8)$ & & $54(25.5)$ & & $47(22.2)$ & & $11(5.2)$ & \\
\hline \multicolumn{9}{|l|}{ Cigarette smoking } \\
\hline No (reference) & $571(36.3)$ & 0.000 & 197(12.5) & 0.000 & $339(21.6)$ & 0.000 & $35(2.2)$ & 0.109 \\
\hline Yes & $357(61.9)$ & & $157(27.2)$ & & 181(31.4) & & $19(3.3)$ & \\
\hline \multicolumn{9}{|c|}{ Alcohol consumption } \\
\hline No (reference) & $684(40.1)$ & 0.000 & $248(14.5)$ & 0.000 & $405(23.7)$ & 0.041 & $31(1.8)$ & 0.000 \\
\hline Yes & $244(55.1)$ & & $106(23.9)$ & & $115(26.0)$ & & $23(5.2)$ & \\
\hline \multicolumn{9}{|c|}{ Family history of HBP } \\
\hline No (reference) & $696(38.1)$ & 0.000 & $231(12.6)$ & 0.000 & $416(22.8)$ & 0.000 & $5(1.6)$ & 0.158 \\
\hline Yes & $232(72.0)$ & & $123(38.2)$ & & $104(32.3)$ & & $49(2.7)$ & \\
\hline
\end{tabular}

Note: compared with the reference by Chi-square test, HBP, high blood pressure; ISH, isolated systolic hypertension; IDH, isolated diastolic hypertension; SDH, systolic-diastolic hypertension

Table 5. Factors associated with the prevalence of hypertension subtypes from multivariate logistic regression models $(n=2150)$

\begin{tabular}{|c|c|c|c|c|c|c|c|c|}
\hline & $\begin{array}{l}\text { Prevalence of } \\
\text { HBP } n(\%)\end{array}$ & OR(95\% CI) & $\begin{array}{l}\text { Prevalence of } \\
\text { SDH } n(\%)\end{array}$ & OR(95\% CI) & $\begin{array}{l}\text { Prevalence } \\
\text { of ISH n(\%) }\end{array}$ & OR(95\% CI) & $\begin{array}{l}\text { Prevalence } \\
\text { of IDH n(\%) }\end{array}$ & OR(95\% CI) \\
\hline \multicolumn{9}{|l|}{ Sex } \\
\hline $\begin{array}{l}\text { Male } \\
\text { (reference) }\end{array}$ & $362(45.9)$ & 1.000 & $175(22.2)$ & 1.000 & $158(20.0)$ & 1.000 & $29(3.7)$ & 1.000 \\
\hline Female & $566(41.6)$ & $\begin{array}{l}1.915(1.506- \\
2.435)\end{array}$ & 179(13.2) & $\begin{array}{l}0.918(0.684- \\
1.232)\end{array}$ & $362(26.6)$ & $\begin{array}{l}2.511(1.905- \\
3.311)\end{array}$ & $25(1.8)$ & $\begin{array}{l}0.763(0.384- \\
1.519)\end{array}$ \\
\hline \multicolumn{9}{|c|}{ Age groups (years) } \\
\hline $\begin{array}{l}50-59 \\
\text { (reference) }\end{array}$ & $289(34.4)$ & 1.000 & $143(17.0)$ & 1.000 & $122(14.5)$ & 1.000 & $24(2.9)$ & 1.000 \\
\hline $60-69$ & $316(45.5)$ & $\begin{array}{l}1.579(1.261- \\
1.976)\end{array}$ & $125(18.0)$ & $\begin{array}{l}0.964(0.726- \\
1.279)\end{array}$ & $175(25.2)$ & $\begin{array}{l}1.976(1.518- \\
2.573)\end{array}$ & $16(2.3)$ & $\begin{array}{l}0.906(0.472- \\
1.739)\end{array}$ \\
\hline $70+$ & $323(52.5))$ & $\begin{array}{l}2.565(2.025- \\
3.249) \\
\end{array}$ & $86(14.0)$ & $\begin{array}{l}0.895(0.654- \\
1.224)\end{array}$ & $223(36.3)$ & $\begin{array}{l}3.411(2.618- \\
4.442)\end{array}$ & $14(2.3)$ & $\begin{array}{l}1.081(0.542- \\
2.159)\end{array}$ \\
\hline \multicolumn{9}{|l|}{ Body weight } \\
\hline Normal & $570(44.4)$ & 1.000 & $235(18.3)$ & 1.000 & $300(17.3)$ & 1.000 & $35(2.7)$ & 1.000 \\
\hline Lean & $246(37.7)$ & $\begin{array}{l}0.718(0.580- \\
0.889)\end{array}$ & $65(10.0)$ & $\begin{array}{l}0.572(0.420- \\
0.779)\end{array}$ & $173(12.5)$ & $\begin{array}{l}0.675(0.5803- \\
0.975)\end{array}$ & $8(1.2)$ & $\begin{array}{l}0.445(0.202- \\
0.981)\end{array}$ \\
\hline Obese & $112(52.8)$ & $\begin{array}{l}1.334(0.968- \\
1.837) \\
\end{array}$ & $54(25.5)$ & $\begin{array}{l}1.255(0.872- \\
1.805)\end{array}$ & $47(22.2)$ & $\begin{array}{l}3.411(2.618- \\
4.442)\end{array}$ & $11(5.2)$ & $\begin{array}{l}1.894(1.033- \\
3.846)\end{array}$ \\
\hline \multicolumn{9}{|c|}{ Cigarette smoking } \\
\hline $\begin{array}{l}\text { No } \\
\text { (reference) }\end{array}$ & $571(36.3)$ & 1.000 & $197(12.5)$ & 1.000 & $339(21.6)$ & 1.000 & $35(2.2)$ & 1.000 \\
\hline Yes & $357(61.9)$ & $\begin{array}{l}3.155(2.506- \\
3.972) \\
\end{array}$ & $157(27.2)$ & $\begin{array}{l}2.219(1.691- \\
2.912) \\
\end{array}$ & 181(31.4) & $\begin{array}{l}2.207(1.719- \\
2.834) \\
\end{array}$ & $19(3.3)$ & $\begin{array}{l}0.985(0.523- \\
1.853) \\
\end{array}$ \\
\hline \multicolumn{9}{|c|}{ Alcohol consumption } \\
\hline $\begin{array}{l}\text { No } \\
\text { (reference) }\end{array}$ & $684(40.1)$ & 1.000 & $248(14.5)$ & 1.000 & $405(23.7)$ & 1.000 & $31(1.8)$ & 1.000 \\
\hline Yes & $244(55.1)$ & $\begin{array}{l}2.101(1.615- \\
2.733)\end{array}$ & $106(23.9)$ & $\begin{array}{l}1.416(1.039- \\
1.930) \\
\end{array}$ & $115(26.0)$ & $\begin{array}{l}1.580(1.182- \\
2.111)\end{array}$ & $23(5.2)$ & $\begin{array}{l}2.400(1.233- \\
4.670)\end{array}$ \\
\hline \multicolumn{9}{|c|}{ Family history of HBP } \\
\hline $\begin{array}{l}\text { No } \\
\text { (reference) }\end{array}$ & $696(38.1)$ & 1.000 & $231(12.6)$ & 1.000 & $416(22.8)$ & 1.000 & $5(1.6)$ & 1.000 \\
\hline Yes & $232(72.0)$ & $\begin{array}{l}\text { 4.463(3.381- } \\
5.892)\end{array}$ & $123(38.2)$ & $\begin{array}{l}4.000(3.038- \\
5.268)\end{array}$ & $104(32.3)$ & $\begin{array}{l}1.703(1.295- \\
2.240)\end{array}$ & $49(2.7)$ & $\begin{array}{l}0.487(0.190- \\
1.249)\end{array}$ \\
\hline
\end{tabular}

Note: 95\% CI, 95\% confidence interval; HBP, high blood pressure; OR, odds ratio; HBP, high blood pressure; ISH, isolated systolic hypertension; IDH, isolated diastolic hypertension; SDH, systolic-diastolic hypertension; 
Table 6. Percentage (\%) of awareness, treatment and control of hypertension subtypes

\begin{tabular}{|l|l|l|l|l|l|l|}
\hline & No. of participants & $\begin{array}{l}\text { Prevalence } \\
\text { N(\%) }\end{array}$ & No. of HBP subtypes & Awareness & Treatment & $\begin{array}{l}\text { Control } \\
\text { N(\%) }\end{array}$ \\
N(\%)
\end{tabular}

Note: HBP, high blood pressure; ISH, isolated systolic hypertension; IDH, isolated diastolic hypertension; SDH, systolic-diastolic hypertension 